\title{
Analysis of an anti-dip landslide triggered by the 2008 Wenchuan earthquake in China
}

\author{
Runqiu Huang $\cdot$ Jianjun Zhao $\cdot$ Nengpan Ju $\cdot$ Guo Li $\cdot$ \\ Min Lee Lee $\cdot$ Yanrong Li
}

Received: 5 December 2012/ Accepted: 28 March 2013/Published online: 11 April 2013

(C) The Author(s) 2013. This article is published with open access at Springerlink.com

\begin{abstract}
The Guantan landslide, with a total displaced mass of about $468 \times 10^{4} \mathrm{~m}^{3}$, was triggered by the 2008 Wenchuan earthquake and succeeding rainfall in Jushui Town, Sichuan Province, China. The landslide occurred on an anti-dip hard rock slope with a weak rock founding stratum of $200 \mathrm{~m}$ in thickness. To investigate the failure mechanism of the Guantan landslide, dynamic behaviors of hard and soft rock slopes were investigated by means of large scale shaking table tests. The laboratory models attempted to simulate the field geological conditions of the Guantan landslide. Sinusoidal waves and actual seismic waves measured from the Wenchuan Earthquake were applied on the slope models under 37 loading configurations. The experimental results indicated that deformation mainly developed at a shallow depth in the upper part of the hard rock slope and in the upper (near the crest) and lower (near the toe) parts of the soft rock slope. An equation for predicting the depth of sliding plane was proposed based on the location of the maximum horizontal acceleration. Finally, it was concluded that the failure process of the Guantan landslide occurred in three stages: (1) toppling failure caused by compression of the underlying soft rock strata, (2) formation of crushed hard rock and sliding surface in soft rock as the result of seismic shocks, particularly in the horizontal direction, and (3) aftershock rainfall accelerates the process of mass movement along the sliding plane.
\end{abstract}

R. Huang · J. Zhao $(\bowtie) \cdot$ N. Ju

State Key Laboratory of Geohazard Prevention and Geoenvironment Protection, Chengdu University of Technology, Chengdu, China

e-mail: zhjjtc@gmail.com

G. Li

Yunnan Provincial Transport Department Broadvision Engineering Consultants, Kunming, China e-mail: ziltch2002@163.com

M. L. Lee

Department of Civil Engineering, Faculty of Engineering and Science, Universiti Tunku Abdul

Rahman, Kuala Lumpur, Malaysia

e-mail: mllee@utar.edu.my

Y. Li

The University of Hong Kong, Hong Kong, China

e-mail: li.dennis@hotmail.com 
Keywords Wenchuan earthquake Landslide Anti-dip slope Shaking table test . Failure mechanism

\section{Introduction}

A disastrous earthquake with a magnitude of 8.0 (MS) struck Wenchuan, Sichuan Province, China on May 12, 2008, at 14:28. The linear epicenter of the earthquake was located from the Yingxiu town to the Beichuan town, about $70 \mathrm{~km}$ northwest of the Chengdu City. The earthquake was caused by reactivation of the Longmenshan mountain fault belt, located between the eastern boundary of the Qinghai-Tibet Plateau and the western part of the Sichuan Basin. The movement of the fault belt caused a rupture in central faults and created a zone of disturbance of over $300 \mathrm{~km}$ in length (Huang and Li 2009a, b). There were about 56,000 rockfalls and landslides triggered directly by the Wenchuan Earthquake, forming 256 barrier lakes (Huang and Li 2009a, b; Xu et al. 2009; Yin et al. 2009; Qi et al. 2010; Wasowski et al. 2011).

Without influences of earthquake and engineering activities, anti-dip slopes with soft rock founding strata are normally not susceptible to catastrophic sudden failures (Zhang et al. 1994). Based on case studies of the Xikou and Touzhai landslides, Huang (2012) proposed a conceptual model to explain failure mechanisms of anti-dip slopes found on soft rock strata. He suggested that the mechanism is analogous to the collapse of a retaining wall in which the rigid mass in the middle or front part of the slope behaves like a "retaining wall". Huang $(1996,2012)$ found that the rock mass above the "retaining wall" generates a toppling failure, while the soft rock beneath the "retaining wall" is under compression. According to field investigations of landslides triggered by the Wenchuan earthquake, it was found that the long-term deformation of the "retaining wall" collapse mechanism suggested by Huang (2012) can be accelerated by earthquakes. Field investigations revealed that numerous large scale landslides occurred on anti-dip slopes after the main shock of the Wenchuan earthquake. For instances, Wangjiayan landslide and Guantan landslide occurred $10 \mathrm{~h}$ (Huang et al. 2012) and $8 \mathrm{~h}$ (Zhao et al. 2010), respectively, after the main shock. Xu et al. (2011) concluded that the anti-dip slopes under seismic loadings failed by mechanisms of tension-cracking-shearing-sliding, while Huang et al. (2011a, b) described this mechanism as shattering-tension-sliding. Both of the geological models proposed by Huang et al. (2011a, b) and Xu et al. (2011) were derived based on general characteristics of main scarps of a number of landslides triggered by the Wenchuan earthquake. For the present Guantan landslide, toppling and compression deformations were observed within the mass of the slope during field investigation. This observation implied that the failure mechanism of the Guantan landslide could be similar to the "retaining wall" collapse mechanism as proposed by Huang (2012).

Studies on mechanisms of earthquake-induced landslides have received great attention over the past decades. Between 1811 and 1997, a total of 76 earthquake events have been documented (Keefer 1984; Rodriguez et al. 1999), resulting in more than 100,000 number of landslides. Wasowski et al. (2011) provided a thorough review of previous, current, and future research studies pertaining to the topic of earthquake-induced landslides. In general, the analysis of dynamic responses and deformations in slopes can be performed by numerical integration (Newmark 1965; Wilson and Keefer 1983; Chang et al. 2005), numerical simulation (Wakai et al. 2009; Zhang et al. 2012), and physical modeling (Wartman et al. 2005; Wang and Lin 2011). Analysis of earthquake-induced landslides 
usually requires information about shearing resistance at the sliding plane of a slope. Shaking table test is widely recognized as a more suitable method to obtain the realistic sliding thresholds of these landslides than the simpler and more convenient tilt test (Hsieh et al. 2011; Severn 2011). Lin and Wang (2006) and Huang et al. (2011a, b) conducted a series of large scale shaking table tests to investigate the dynamic behaviors of soil slopes under seismic loading. They found that the failure planes observed in shaking table tests showed good comparisons with field observations (Lin et al. 2006; Huang et al. 2011a, b). Wang et al. (2010) carried out both shaking table tests and numerical simulations on an anti-dip rock slope composed of weak layers. They indicated that the amplification factor of Peak Ground Acceleration (PGA) on slope surface increased with height. Xu et al. (2010) studied the seismic responses of two slope models composed of layered hard and soft rocks. They indicated that vertical tension cracks appeared as the dominant edges (or boundaries) of earthquake-induced landslides, and PGA was related to both height and lithology.

The present study attempts to investigate the failure mechanism of a landslide (known as the Guantan landslide) triggered by the 2008 Wenchuan earthquake and to unravel the earthquake impacts on the anti-dip hard rock slope underlying by a soft rock strata. Tectonic and geologic settings and characteristics of the Guantan landslide are first reported, followed by the results of a series of shaking table tests simulating the seismic and geological conditions of the field slope. The failure mechanism of the Guantan landslide is then deduced based on the deformation and acceleration amplification coefficient of PGA measured from the laboratory models.

\section{Geological settings}

\subsection{Geological background}

Over $75 \%$ of the historical earthquake-induced landslides worldwide involve rockfalls/ slides (Rodriguez et al. 1999). Geological settings and lithological characteristics have been identified as the dominant contributing factors to these landslides (Chigira and Yagi 2006). Figure 1 shows the regional geological map of the Longmensgan area. The Longmenshan area is located at the eastern boundary of an active tectonic block known as Bayan Har Block. Since the seventieth century, twelve earthquakes with $M(S)$ ranging from 6.5 to 8.0 have been recorded along the eastern boundary of the Bayan Har Block (Wen et al. 2009; Wang et al. 2011). The Longmenshan mountain fault belt, including the frontal, central, and back faults, forms the boundaries of the western Sichuan Plateau, the Chengdu Plain, and the Bayan Har Block.

The Guantan landslide is located at about $11 \mathrm{~km}$ from the central fault and $360 \mathrm{~m}$ from the frontal fault, both of which were reactivated during the Wenchuan Earthquake. The slope is located at the right bank of the Jushui River. Before the landslide occurrence, the original Guantan slope dipped to east with a slope gradient of about $40^{\circ}$. The altitudes of the crest and river bed were 1,300 and $680 \mathrm{~m}$, respectively, forming a vertical height of about $620 \mathrm{~m}$. Geologically, the landslide area is located on the southeast wing of the Hanwang Inverted Syncline, the northwest wing of the Dapingshan Anticline, and the upper plate of the frontal fault. The frontal fault, with a shattered fault zone of 5-20 m in thickness, was partially reactivated during the Wenchuan Earthquake. It generated seismic cracks of $16 \mathrm{~km}$ in length on the ground in the direction of $45^{\circ}$ from the Jushui town to the Feishui town. 

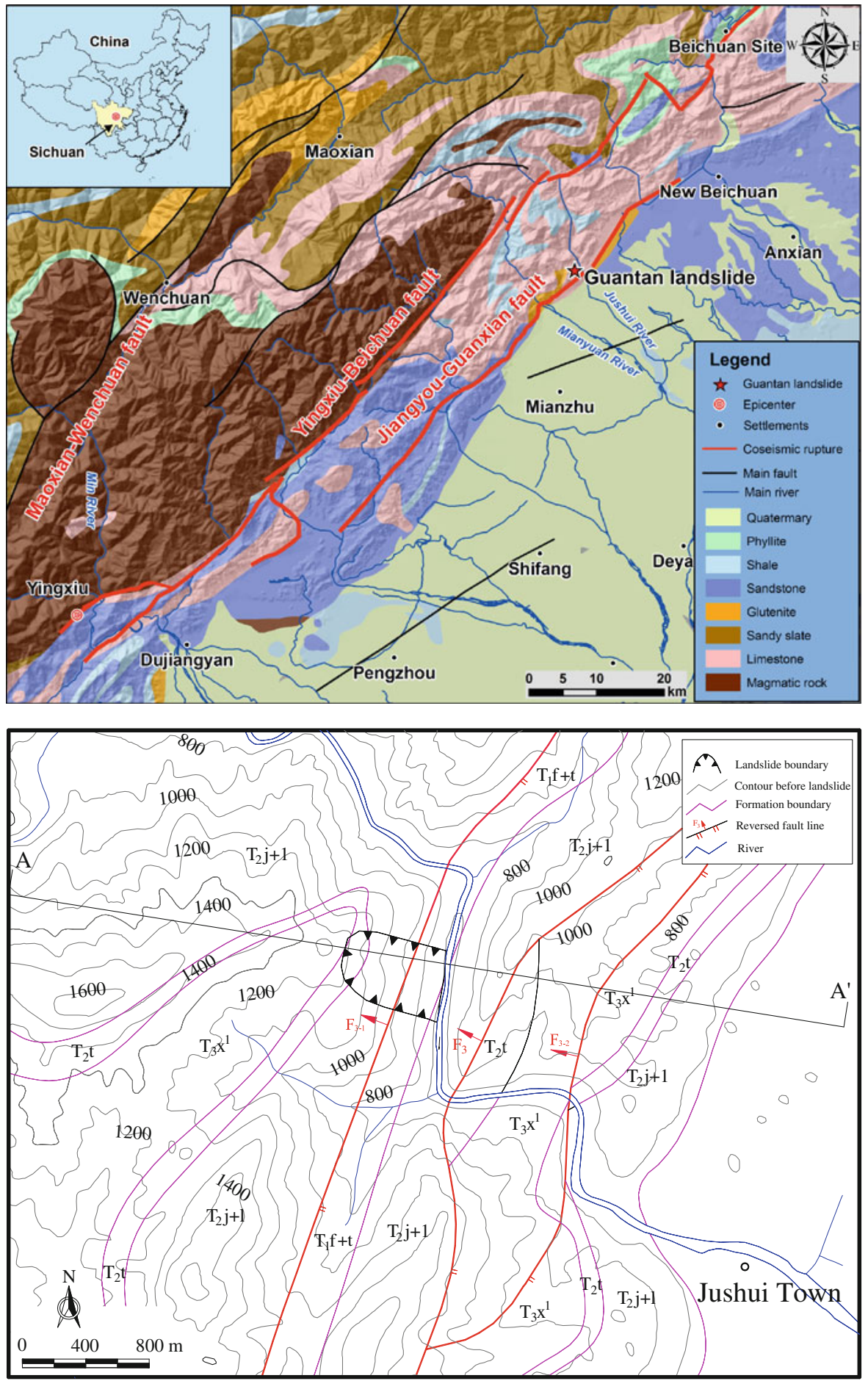

Fig. 1 Regional geological map of the Longmenshan area 
Geological formations in the area can be categorized into four main groups (refer to Fig. 2), namely: (1) the Triassic Xujiahe group $\left(\mathrm{T}_{3} \mathrm{x}\right)$, (2) the Triassic Tianjingshan group $\left(T_{2} t\right)$, (3) the Triassic Jialingjiang and Leikoupo group $\left(T_{2} j+1\right)$, and (4) the Triassic Feixianguan and Tongjiezi group $\left(T_{2} f+t\right)$. The upper $T_{3} x$ group is composed of gray massive sandstone distributing on top of mountain. The rocks in the middle $\mathrm{T}_{2} \mathrm{t}$ group and $\mathrm{T}_{2} \mathrm{j}+1$ group are mainly limestone and dolomite. The bottom $\mathrm{T}_{2} \mathrm{f}+\mathrm{t}$ group consists of alternating thin beds of purplish red sandstone, pelitic siltstone, and mudstone.

A branch (denoted as $F_{3-1}$ in Fig. 1) of the frontal fault $\left(F_{3}\right.$ in Fig. 1) cut through the center of the landslide area in the transverse direction and formed the interface between the overlying hard rocks (limestone and dolomite of $\mathrm{T}_{2} \mathrm{j}+1$ ) and the underlying incompetent rocks (mudstone and pelitic siltstone of $\mathrm{T}_{1} \mathrm{f}+\mathrm{t}$ ). Groundwater in the bedrock consisted of mainly fissure water. Development of fissure-karst water was deemed to have taken place as significant karstification and calcareous cement were observed on the surface of dolomite stones and in the landslide deposits, respectively.

\subsection{Characteristics of the landslide}

Figure 2 shows the geological profile of the Guantan slope prior to the landslide occurrence. The Guantan landslide was characterized by an anti-dipping structure with a soft rock founding stratum. The failure occurred on May 12, 2008, at 22:30, $8 \mathrm{~h}$ after the Wenchuan earthquake. It was located at $4 \mathrm{~km}$ upstream of the Jushui Town. According to descriptions of witnesses in the Jushui town, the earthquake shaking was extremely strong. There were numerous aftershocks and heavy rains after the main shock. At 22:00, loud rumbling noises were heard, and the rock falling sounds persisted for $1 \mathrm{~h}$. Rock masses with a volume of 4.68 million $\mathrm{m}^{3}$ slid down into the Jushui river, forming a debris-dam with a catchment volume of 20 million $\mathrm{m}^{3}$. To prevent catastrophic breaking of the impounded water behind the dam and consequent disasters, the dam was excavated, forming a slope of $50 \mathrm{~m}$ high and $260 \mathrm{~m}$ long in front of the landslide deposits. The natural slope prior to landslide was composed of inward dipping hard rocks (dolomitite) overlying soft rocks (mudstone).

A fault, $\mathrm{F}_{3-1}$, cut through the slope at a height of $150 \mathrm{~m}$ above river bed. The dip direction and dip angle of the fault were $315^{\circ}$ and $70^{\circ}$, respectively. The lower plate of the fault was alternating thin beds of purplish red mudstone and sandstone of $\mathrm{T}_{1} \mathrm{f}+\mathrm{t}$ group with a thickness of $200 \mathrm{~m}$. Besides, there were a set of discontinuities with a dip direction

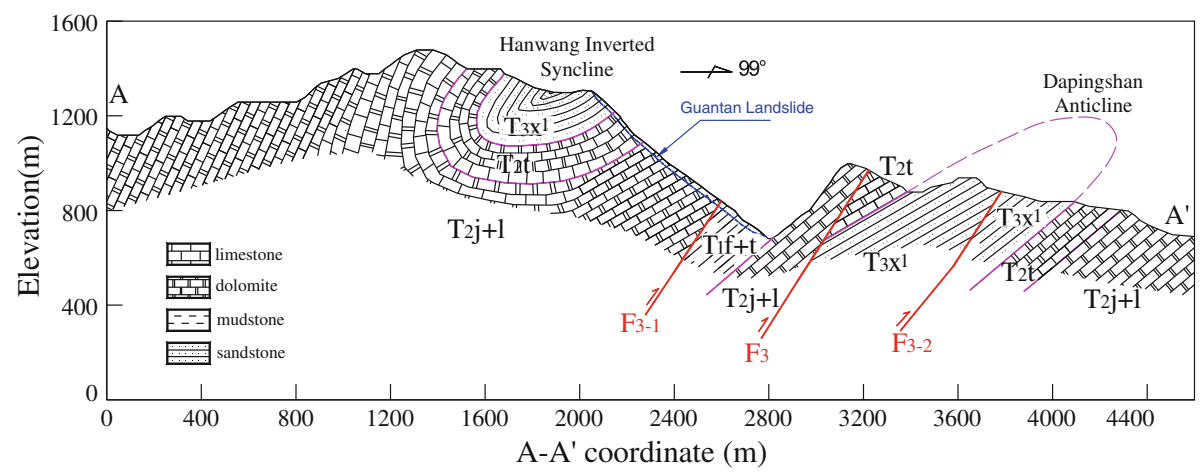

Fig. 2 Engineering geological profile 
of $102^{\circ}$ and a dip angle of $82^{\circ}$. The upper plate of the fault was limestone and dolomite of $\mathrm{T}_{2} \mathrm{j}+1$ group and $\mathrm{T}_{2} \mathrm{t}$ group. There were two sets of joints, in which one of them struck $358^{\circ}$ and dipped $66^{\circ}$ to the NE and the other set struck $25^{\circ}$ and dipped $36^{\circ}$ to the SE.

For clarity, the landslide area was divided into four zones, that is, the main scarp at the northwest, the left and right flanks of rupture surfaces at the northeast and southwest, respectively, and the toe area at the southeast (Fig. 3). The top elevation of the main scarp was $1,270 \mathrm{~m}$. The scarp has a vertical distance of $20 \mathrm{~m}$ and a slope angle of $70^{\circ}$. Heavily weathered gray limestone and dolomite were outcropped, in which the strata struck $25^{\circ}$ and dipped $35^{\circ}$ SE. The rupture surfaces at both flanks were controlled by original gullies. Gullies that remained in their original shapes with a trend of $286^{\circ}$ and a slope angle of $60^{\circ}$ were observed at the northeast flank. The southwest flank of rupture surface was exposed in an escarpment with a strike of $265^{\circ}-286^{\circ}$ and a slope angle of about $60^{\circ}$.

In the southeast area, the sliding mass formed a debris-dam that blocked the Jushui River. The structure of the landslide deposits was revealed by observing the components of this debris-dam. It was found that the sequence of beddings of the landslide deposits was similar to that of the original slope. However, the dip angle changed distinctly (See Table 1). In addition, the interface between $T_{1} f+t$ group and $T_{2} j+1$ group in the slope was investigated by observing the surface of the debris-dam. The investigation result indicated that the difference in height between these two interfaces was $67 \mathrm{~m}$ (Fig. 3).

Based on the field investigation results coupled with the topographical and geological information collected in the study area, a general hypothetic model was established to illustrate the main characteristics of the Guantan landslide: (1) the sliding area was located between two causative faults, that is, the southeast wing of the Hanwang Inverted Syncline and the northwest wing of the Dapingshan Anticline, (2) the slope was composed of a hard rock stratum underlain by a soft rock stratum with inward dipping bedding planes, (3) the sliding plane was about $40 \mathrm{~m}$ below the terrain surface, (4) the phenomenon of deformation indicated that the slope exhibited complete toppling and sliding failures, (5) the main shock and aftershocks of the Wenchuan earthquake resulted in crushed dolomite and

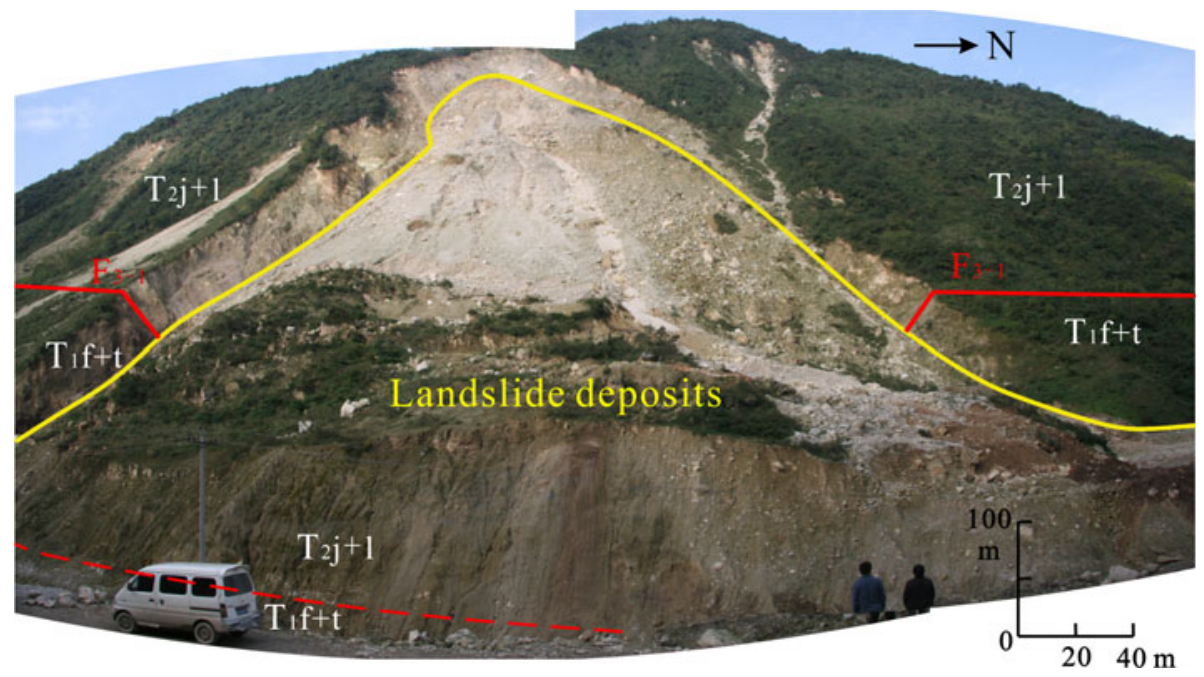

Fig. 3 Zoning photograph of the landslide (the red dotted line refers to the interface of mudstones and domolite stones in the landslide deposits) 
Table 1 Variation of the orientation of rock strata

\begin{tabular}{llll}
\hline Formation & Attitude of beddings & & Change in angle \\
\cline { 2 - 3 } & Before landslide & Post-landslide & \\
\hline $\mathrm{T}_{1} \mathrm{f}+\mathrm{t}$ & N34E/NW57 & N31E/NW9 & $48^{\circ}$ \\
$\mathrm{T}_{2 \mathrm{j}}+1$ & $\mathrm{~N} 25 \mathrm{E} / \mathrm{NW} 35$ & N26E/NW19 & $16^{\circ}$ \\
\hline
\end{tabular}

limestone, and the succeeding rainfall triggered the landslide, and (6) the main sliding direction of the landslide was $99^{\circ}$, the height of the landslide was $500 \mathrm{~m}$, and the volume of sliding deposit was 4.68 million $\mathrm{m}^{3}$.

\section{Methodology}

Field observations were undertaken in the Wenchuan earthquake-affected regions between 2008 and 2009. Detailed investigations of the Guantan landslide were carried out in 2009. A series of shaking table tests were then conducted to simulate the dynamic behaviors of the Guantan landslide. Finally, a qualitative analysis was performed to deduce the failure mechanism of the Guantan landslide based on geological characteristics of the study area and results of the laboratory shaking table test.

\subsection{Field investigations}

Initial investigation of the landslides triggered by the Wenchuan earthquake indicated that most of the large scale landslides on anti-dip slopes were characterized by post-seismic deformation (Huang et al. 2012), among which the Guantan landslide was a typical landslide of the kind (Zhao et al. 2010). Prior to field investigations, a desk study was carried out to collect information about seismic characteristics of the Wenchuan earthquake and geological settings of the study area. Digital geological maps at scales of 1:200,000 and 1:50,000 were used to identify the locations of faults and lithological features of bedrock. A number of site investigations were scheduled between 2008 and 2009 to determine the failure characteristics and pre-failure structures of the slope. Boundary and volume of the sliding masses were surveyed during the site investigations. Photographs were captured to reveal the sliding plane, sliding mass deposition, exposed strata, and geological features of rocks. In addition, rock samples were collected for testing the engineering properties in laboratory. Based on the field data collected, digital topography maps before and after the Guantan landslide were plotted at a scale of 1:500.

\subsection{Shaking table test}

Since the Guantan slope was not instrumented prior to the landslide occurrence, it was difficult to perform a quantitative assessment on the propagation mechanism of the landslide deformation. The validity of the failure mechanism that deduced from the qualitative field observations and limited field investigation data could be questionable. The antidipping hard rock stratum overlying a soft rock stratum of the Guantan landslide constitutes an interesting geological formation that worth an insightful investigation for clarifying how these attributes provoke slope instabilities under seismic loadings. For these 
reasons, a series of laboratory shaking table tests were conducted to simulate the dynamic responses of the hard and soft rock strata of the Guantan landslide.

Table 2 tabulates the specifications of the shaking table test. Two anti-dip slope models $(1.7 \times 1.5 \times 1.2 \mathrm{~m}$ as shown in Fig. 4) were set up, with one containing hard rock and another was placed with soft rock. The hard rock model simulated the limestone slope, while the soft rock model simulated the mudstone slope in accordance with the geological conditions of the Guantan landslide. The law of similitude after Xu et al. (2010) was adopted for determining dynamic testing conditions of the models. The law of similitude was applied to ensure that the laboratory shaking table test exhibited a similar physical phenomenon to that of the actual field slope. In general, three major criteria were considered during the setting-up of the laboratory model:

1. Gravity acceleration is an important parameter governing dynamic responses of a slope. The gravity acceleration similarity ratio $\left(C_{a}\right)$ can be reasonably taken as unity in view of the gravity acceleration at the field should not vary considerably from the laboratory.

2. The movement of a landslide relies on the shearing resistance of the slope mass that mainly characterized by the coefficient of friction. Therefore, it is important to ensure that the materials forming the laboratory model possess similar engineering properties to that of the actual field slope.

3. The setup is constrained by the limitations of the laboratory shaking table, that is, dimension, maximum acceleration capacity, maximum load capacity, etc.

Based on the considerations above, a 1/100 scaled laboratory model was selected in this study. The similarity ratios for other experimental parameters are tabulated in Table 3. Table 4 shows the comparisons between engineering properties of the materials forming the laboratory slope models and the actual field slope (Xu et al. 2010). The materials in the laboratory slopes were mainly formed by barite powder, quartz sand, plaster, and glycerin at ratios of 44.9:32.0:12.8:9.0:1.3 for the hard rock slope; and at ratios of 51.3:32.0:9.0:6.4:1.3 for the soft rock slope. These mixture proportions were obtained by trial and error.

Prefabricated blocks and cements were used to simulate the hard rocks and discontinuities, respectively. Bedding planes were simulated by stacking the prefabricated blocks in layers. Discontinuities were simulated by providing discontinuous bonding at the

Table 2 Specifications of the shaking table apparatus

\begin{tabular}{ll}
\hline Size of table & $6 \mathrm{~m} \times 6 \mathrm{~m}$ \\
\hline $\begin{array}{l}\text { Frequency range of wave } \\
\text { Loading modes }\end{array}$ & $\begin{array}{l}0.1-100 \mathrm{~Hz} \\
\text { Six degrees of freedom } \\
\text { with three directions }\end{array}$ \\
Maximum load force & $600 \mathrm{kN}$ \\
Maximum displacement & \\
Horizontal & $\pm 150 \mathrm{~mm}$ \\
Vertical & $\pm 100 \mathrm{~mm}$ \\
Maximum acceleration & \\
Horizontal & $1 \mathrm{~g}$ \\
Vertical & $0.8 \mathrm{~g}$ \\
\hline
\end{tabular}


Fig. 4 Locations of accelerometers in the model (dimensions in unit: $\mathrm{cm}$ )
Table 3 Similitude ratios of laboratory model parameters

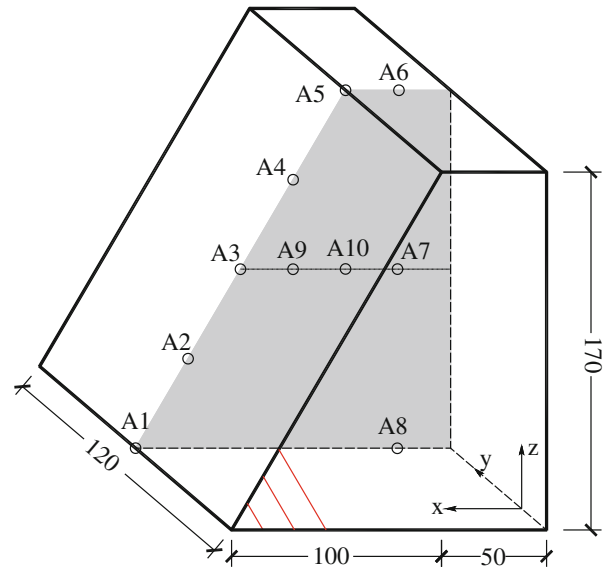

\begin{tabular}{ll}
\hline Properties & Similarity ratio \\
\hline Geometric dimensions, $L$ & $C_{L}=100$ \\
Density, $\rho$ & $C_{\rho}=1$ \\
Shaking acceleration, $a$ & $C_{a}=1$ \\
Unit weight, $\gamma$ & $C_{\gamma}=C_{\rho}=1$ \\
Elastic Modulus, $E$ & $C_{E}=C_{\rho} C_{L}=100$ \\
Poisson's ratio, $\mu$ & $C_{\mu}=1$ \\
Coefficient of friction, $f$ & $C_{f}=1$ \\
Internal cohesion, $c$ & $C_{c}=C_{\rho} C_{L} C_{a}=100$ \\
Internal friction angle, $\phi$ & $C_{\phi}=1$ \\
\hline
\end{tabular}

Table 4 Physical and mechanical parameters of the actual field and simulated materials

\begin{tabular}{llllllll}
\hline $\begin{array}{l}\text { Hard } \\
\text { rockType } \\
\text { of rocks }\end{array}$ & $\begin{array}{l}\text { Unit } \\
\text { weight, } \gamma \\
\left(\mathrm{kN} / \mathrm{m}^{3}\right)\end{array}$ & $\begin{array}{l}\text { Elastic } \\
\text { modulus, } \\
E(\mathrm{MPa})\end{array}$ & $\begin{array}{l}\text { Poisson's } \\
\text { ratio, } \mu\end{array}$ & $\begin{array}{l}\text { Cohesion, } \\
c(\mathrm{MPa})\end{array}$ & $\begin{array}{l}\text { Internal } \\
\text { friction } \\
\text { angle, } \phi \\
\left({ }^{\circ}\right)\end{array}$ & $\begin{array}{l}\text { Cohesion } \\
\text { along } \\
\text { bedding } \\
\text { plane, } \\
c(\mathrm{MPa})\end{array}$ & $\begin{array}{l}\text { Friction } \\
\text { angle along } \\
\text { bedding } \\
\text { plane, } \phi\left(^{\circ}\right)\end{array}$ \\
\hline $\begin{array}{l}\text { Hard rock } \\
\text { Actual }\end{array}$ & $26.5-27.5$ & $6,000-9,000$ & 0.25 & $5-50$ & $38-45$ & $0.5-1.0$ & $35-40$ \\
$\begin{array}{l}\text { Simulated } \\
\text { Soft rock }\end{array}$ & 27.3 & 73.7 & 0.25 & 0.12 & 43 & 0.006 & 37 \\
$\begin{array}{l}\text { Actual } \\
\text { Simulated }\end{array}$ & $26-27$ & $1,000-3,000$ & 0.28 & $0.5-5$ & $30-38$ & $0.05-0.5$ & $25-30$ \\
\hline
\end{tabular}

interface between blocks within a same layer using cements. Boards were used for layerby-layer pouring in the soft rock model. Bedding planes were simulated by ordinary paper.

Ten accelerometers were installed along three measurement directions (Table 5), denoted as A1-A10 in Fig. 4. Accelerometers A1, A2, A3, A4, and A5 were placed on the 
slope surface. Accelerometers A3, A9, A3, A10, and A7 were embedded at various depths in the slope to monitor the accelerations along the horizontal direction, while A8, A7, and A6 were oriented to monitor the accelerations along the vertical direction. To minimize the side boundary effect, all the sensors of accelerometers were embedded into center of the slope model. The bottom boundary effect was minimized by laying an additional $20-\mathrm{cm}-$ thick buffer layer which was made of similar materials forming the slope at the base of the model.

Signals recorded from the accelerometers were subjected to undesired noise interferences. It is necessary to perform an appropriate data transformation before the data can be readily used for subsequent analyses. In general, there were three techniques of data transformation applied in this study, namely pre-filtering, zero-mean normalization, and removal of errors. Pre-filtering was used to smooth the signal data set, control their frequency bandwidths, and reduce noises of high frequencies. Zero-mean normalization that involved rescaling of attributes was used to analyze statistical characteristics of the captured signals. The value of an attribute was normalized using the mean and standard deviation of a data set. Removal of errors was used to eliminate error data points that could be caused by external disturbances or inconsistency of the instruments. Upon data reduction, it was essential to ensure that the new data set preserved the integrity of the original data set.

In the shaking table test, it is very difficult if not impossible to determine accurately the propagation of the slope failure by visual observation. A typical slope structure tends to possess specific seismic parameters that would respond correspondingly when failure is initiated. By processing and interpreting the responses of the seismic signals, the shearing plane and failure mode of a slope can be evaluated quantitatively. In the present study, the Hilbert-Huang transform (HHT) data-processing technique was adopted to characterize the seismic responses of the slope models. Detailed explanations of the technique in earthquake engineering applications have been reported by numerous researchers including Wei et al. (2010), Zhang et al. (2003), etc. One of the advantages of the HHT over the commonly used Fourier transform is that the HHT could give a better interpretation on variations of nonlinear signals caused by a structural damage during the signal transduction. The HHT technique uses the concept of empirical mode decomposition (EMD) to decompose signals into the intrinsic mode function (IMF). Through Hilbert spectral analysis of the IMF, the time-frequency characteristics of a signal can be obtained, and hence, the occurrence time and variation amount of the signal can be deduced. These features are important for determining the exact location and time of the slope mass starting to deform under seismic loadings.

Two types of seismic waves, that is, sinusoidal wave and in situ measured seismic wave, were applied to the models. The frequencies of the sinusoidal wave were 5, 10, and $15 \mathrm{~Hz}$. The in situ waves were recorded from the Wolong seismostation during the Wenchuan earthquake, which is located at the Wolong Town of the Wenchuan County, $114 \mathrm{~km}$ away from the Guantan landslide site. Both the waves were applied in horizontal $X$ direction and vertical $Z$ direction.

Table 5 Parameters of accelerometers used

\begin{tabular}{llll}
\hline Type & $\begin{array}{l}\text { Sensitivity } \\
\left(\mathrm{mV} / \mathrm{ms}^{2}\right)\end{array}$ & $\begin{array}{l}\text { Frequency } \\
\text { range }(\mathrm{Hz})\end{array}$ & $\begin{array}{l}\text { Measuring } \\
\text { range }\left(\mathrm{m} / \mathrm{s}^{2}\right)\end{array}$ \\
\hline DH301 & $\sim 66$ & $0-1,500(X)$ & 20 \\
& $(X, Y, Z)$ & $\begin{array}{l}0-1,500(Y) \\
0-800(Z)\end{array}$ & \\
\hline
\end{tabular}


Thirty-seven seismic wave loading configurations (Table 6) were designed to study the dynamic responses at different amplitudes of seismic waves and to determine the critical accelerations of deformation and damage in the slope models during earthquakes. Firstly, small-amplitude sinusoidal waves and in situ waves were applied. The amplitude of the in situ waves was then increased gradually. Finally, sinusoidal waves and in situ waves were loaded alternately until the models were completely destroyed. The duration of each test configuration was $10.8 \mathrm{~s}$ in accordance with the similitude principle (Xu et al. 2010) at an interval of $15 \mathrm{~min}$.

\section{Results}

\subsection{Deformation process}

Figure 5a, b show the photographs of the hard rock and soft rock slope models, respectively, prior to complete failures. For clearer presentations, the deformation characteristics of the two models are illustrated in Fig. 6a, b, respectively. For the hard rock slope, toppling and fractures were observed in the upper part (near the crest) of the slope during the initial stage. Subsequently, numerous tension cracks developed along the bedding planes and intercepted by new fissures (Figs. 5a, 6a). An upheaval deformation was observed on the slope surface near the exit of the sliding plane. Rock masses were dislocated by the sliding plane at the crest of the slope before the slope failed completely. The failure plane along the joints exhibited a polygonal-shaped surface. The trailing edge was

Table 6 Thirty-seven configurations of seismic waves loaded on the modeled slopes

\begin{tabular}{|c|c|c|c|c|c|c|c|}
\hline Number & Waves & Direction & Amplitude (g) & Number & Waves & Direction & Amplitude (g) \\
\hline 1 & White & I & 0.05 & 20 & $\mathrm{~N}$ & $Z$ & 0.2 \\
\hline 2 & $\mathrm{~S}(5 \mathrm{HZ})$ & $Z$ & 0.1 & 21 & $\mathrm{~N}$ & $X$ & \\
\hline 3 & $\mathrm{~S}(10 \mathrm{HZ})$ & & & 22 & White & l & 0.1 \\
\hline 4 & $\mathrm{~S}(15 \mathrm{HZ})$ & & & 23 & $\mathrm{~N}$ & $Z$ & 0.3 \\
\hline 5 & White & I & 0.05 & 24 & $\mathrm{~N}$ & $X$ & \\
\hline 6 & $\mathrm{~S}(5 \mathrm{HZ})$ & $X$ & 0.1 & 25 & White & I & 0.1 \\
\hline 7 & $\mathrm{~S}(10 \mathrm{HZ})$ & & & 26 & $\mathrm{~N}$ & $Z$ & 0.4 \\
\hline 8 & $\mathrm{~S}(15 \mathrm{HZ})$ & & & 27 & $\mathrm{~N}$ & $X$ & \\
\hline 9 & White & I & 0.05 & 28 & White & I & 0.1 \\
\hline 10 & $\mathrm{~N}$ & $Z$ & 0.1 & 29 & $\mathrm{~N}$ & $Z$ & 0.5 \\
\hline 11 & $\mathrm{~N}$ & $X$ & & 30 & $\mathrm{~N}$ & $X$ & \\
\hline 12 & $\mathrm{~S}(5 \mathrm{HZ})$ & $Z$ & 0.2 & 31 & White & l & 0.1 \\
\hline 13 & N (10 HZ) & & & 32 & $\mathrm{~N}$ & $Z$ & 0.6 \\
\hline 14 & N (15 HZ) & & & 33 & $\mathrm{~N}$ & $X$ & \\
\hline 15 & White & I & 0.1 & 34 & White & l & 0.1 \\
\hline 16 & $\mathrm{~N}(5 \mathrm{HZ})$ & $X$ & 0.2 & 35 & $\mathrm{~N}$ & Z & 0.8 \\
\hline 17 & $\mathrm{~N}(10 \mathrm{HZ})$ & & & 36 & $\mathrm{~N}$ & $X$ & \\
\hline 18 & $\mathrm{~N}(15 \mathrm{HZ})$ & & & 37 & White & I & 0.1 \\
\hline 19 & White & I & 0.1 & & & & \\
\hline
\end{tabular}

$S$ sinusoidal waves, $N$ natural waves of the Wenchuan earthquake 
steep, while the frontier was flat. Deformations mainly focused in the region of higher than $2 / 5$ of slope height from the ground and within a horizontal depth of $1 / 3$ of slope height.

The deformations of soft rock slope varied to a certain extent from the hard rock slope (Figs. 5b, 6b). Toppling - bending failures with less fresh fractures in the rock mass were observed in the region higher than $2 / 5$ of slope height from the ground. Shear-sliding failures developed along the bending parts in the slope and formed distinct downward dislocation with fresh cracks at the crest of the slope. The failure surface was similar to that of hard rock, but in a flatter and more regular shape. Fractures developed through the bedding planes at the bottom of the model before a complete sliding failure occurred.

From the foregoing observations, it can be concluded that the deformations induced by earthquake mainly occurred at the upper part of the slope. Numerous fresh fractures were formed in the hard rock resulting in cataclastic structures. The number of fresh fractures in the soft rock was significantly less than that of hard rock. A continuous siding plane was formed in the soft rock slope. In addition, large deformations with continuous shear cracks and slope surface upheavals were observed near the toe of the soft rock slope.

\subsection{Acceleration in the slope models}

Peak Ground Acceleration (PGA) was measured by the ten acceleration sensors installed in the slope model. To explain deformation phenomena occurred in the slope, the acceleration amplification coefficient of PGA was adopted to study the dynamic responses of the slope under earthquake loading. The acceleration amplification coefficient in this paper refers to the ratio of the PGA measured within the slope to that of measured at the toe of the slope. Vertical and horizontal PGA were measured when vertical (in $\mathrm{Z}$ direction) and horizontal (in $\mathrm{X}$ direction) seismic waves were loaded, respectively.
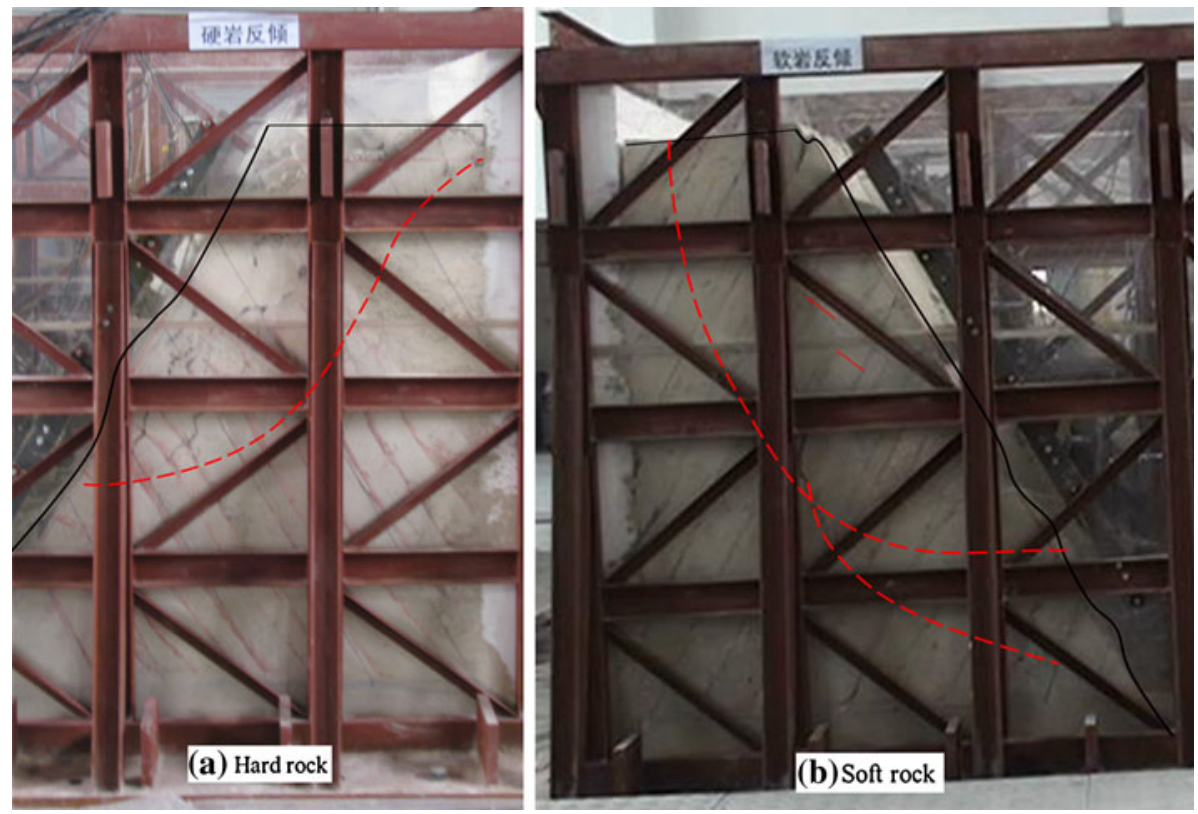

Fig. 5 Photographs of the a hard rock and $\mathbf{b}$ soft rock slope models before complete failure 
Fig. 6 Deformation characteristics of the a hard rock and b soft rock slope models before complete failure

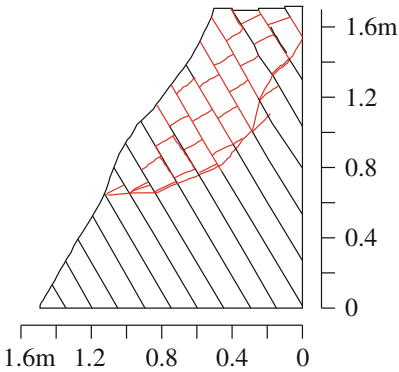

(a) Hard rock model

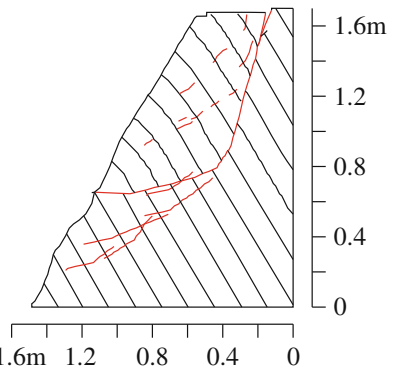

(b) Soft rock model

Figures 7 and 8 show the variations of vertical and horizontal acceleration amplification coefficient of PGA, respectively, when seismic waves with an amplitude of $0.2 \mathrm{~g}$ and frequencies of 5, 10, and $15 \mathrm{HZ}$ were loaded. As shown in Fig. 7, the vertical acceleration amplification coefficients obtained from different seismic wave frequencies were reasonably consistent for the two models. On the slope surface, the vertical acceleration amplification coefficients of the low-frequency waves were slightly greater than those of the high-frequency waves.

The horizontal acceleration amplification coefficients of the high-frequency waves were significantly larger than those of the low-frequency waves when horizontal waves were applied. The horizontal amplification effect was distinctly different for the two studied slope models. For the hard rock slope as shown in Fig. 8a, the horizontal acceleration amplification coefficients on the surface increased sharply beyond $1 / 4$ of total slope height from the ground (A2' in Fig. 8a). The horizontal acceleration amplification coefficients captured within 1/4 horizontal distance from the slope surface (A3' and $A 9^{\prime}$ in Fig. 8a) were higher than those of deeper depths. For the soft rock slope (Fig. 8b), the horizontal

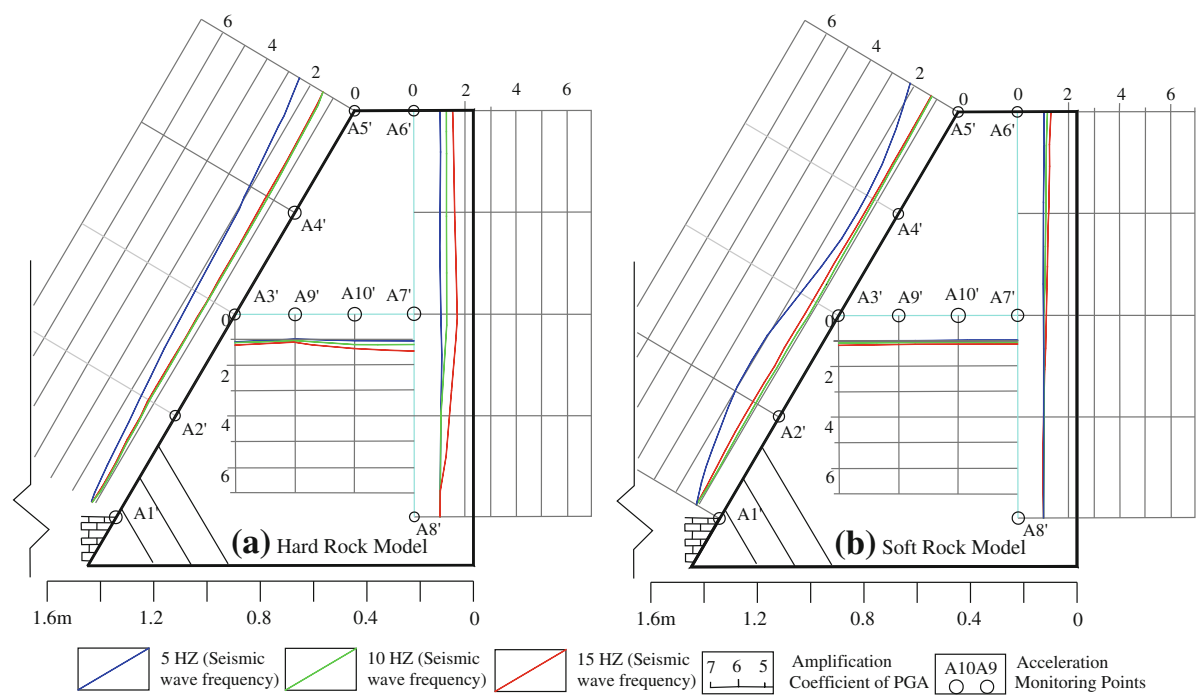

Fig. 7 Variations of vertical acceleration amplification coefficient of PGA when vertical waves of sine wave with an amplitude of $0.2 \mathrm{~g}$ were loaded: a hard rock slope and $\mathbf{b}$ soft rock slope 


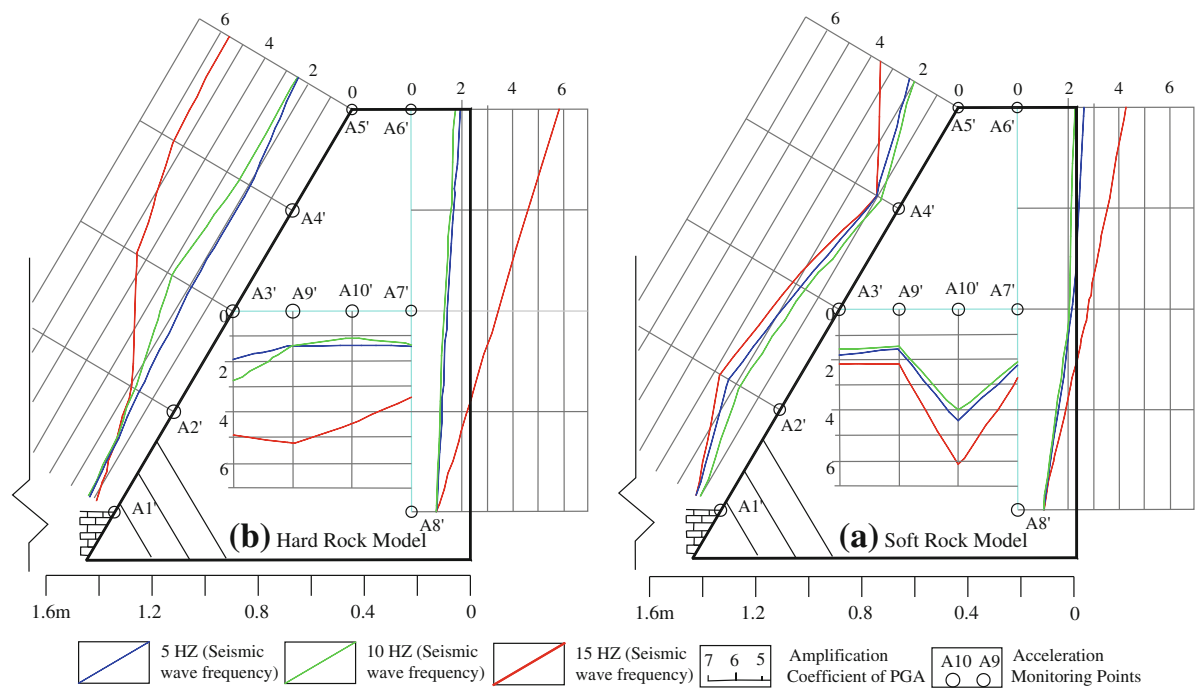

Fig. 8 Variations of horizontal acceleration amplification coefficient of PGA when horizontal waves of sine wave with an amplitude of $0.2 \mathrm{~g}$ were loaded: a hard rock slope and $\mathbf{b}$ soft rock slope

amplification coefficients on the slope surface at $1 / 4$ (A2' in Fig. 8b) and full (A5' in Fig. 8 b) slope heights from the ground were particularly high, that is, ranging from 2 to 3.5. The horizontal amplification coefficients were the highest at $1 / 2$ horizontal distance from the slope surface ( $\mathrm{A} 10^{\prime}$ in Fig. 8b). Apparently, the locations that recorded the maximum horizontal acceleration amplification coefficients were consistent with the severely deformed masses, as indicated by the continuous red lines in Fig. 6.

From the shaking table test results, three general findings were drawn for clarifying the impact of seismic waves on slopes with inward dipping bedding planes: (1) the impact of the horizontal seismic wave is larger than that of vertical seismic wave, (2) the impact of seismic waves on the hard rock slope is mainly limited to a shallow depth at the upper part of the slope, (3) the impact of seismic waves on the soft rock slope mainly focuses on upper and lower parts of the slope surface and at a deeper depth than that of the hard rock slope.

\section{Discussion}

\subsection{Failure mechanism}

Based on the field investigation and laboratory modeling results, the deformation process of the Guantan landslide can be summarized into three stages:

1. Toppling deformation caused by compression of the underlying soft rock stratum

Groundwater motion was active before the landslide as deduced from the phenomenon of karstification on the stones in the landslide debris. In addition, the hard rock stratum in the Guantan slope was sitting on the upper plate of the fault F3-1 (refer to Figs. 1, 2). Fractures developed in the dolomite and limestone have created a favorable condition for groundwater migration. It was difficult for the groundwater to discharge at the interface of hard rock and 
soft rock because of the inward dipping bedding planes. Under such circumstances, the underlying mudstones were softened by the rising groundwater table as a result of rainfall infiltration. It is hypothesized that compression-toppling deformation may have developed in the natural slope prior to the triggering earthquake, as illustrated in Fig. 9.

2. The earthquake results in crushed hard rocks at a shallow depth and forms a sliding surface in the soft rock stratum

The hard rock mass within about $40 \mathrm{~m}$ of horizontal depth from the slope surface was crushed by the Wenchuan earthquake, as indicated by the toppling deformation. A similar observation has been reported by Katz et al. (2011) in their case study in Jerusalem, Israel, in which crushed rock blocks were formed as results of tensile stresses and associated fracturing in the dolomite. According to Fig. 6, the impact of earthquake mainly focused in the upper part of the hard rock slope. The extent of rock crushing in the lower part of the hard rock mass was relatively not as critical as that in the upper part. In addition, long shearing cracks were generated in the underlying soft rock at a depth of about $42 \mathrm{~m}$ from the slope surface (Fig. 10). The sliding surface of the landslide was not continuous at the lower part of the hard rocks. After earthquake, creeping deformation was initiated from the upper part of the slope and was blocked near the interface between hard and soft rock layers (Fig. 10). Subsequently, the cracks in the lower part of the hard rock were generated gradually as a result of strong stresses/impacts generated from the upper deformed slope.

\section{Rainfall succeeding earthquake accelerated the process of sliding}

Numerous historical earthquake-induced landslides have been associated to rainfalls preceding or succeeding the earthquake events, that is, landslides triggered by the 1995 Bafaka, Cameroon earthquake (Ayonghe et al. 1999); the 2004 Niigata-Ken Chuetsu, Japan earthquake (Kieffer et al. 2006); the 1999 Chi-Chi, Taiwan earthquake (Lin et al. 2006), etc. In the present Guantan landslide, the intense rainfall succeeding the earthquake was also identified as one of the main contributing factors to the landslide. As the rock masses were crushed by the impact of earthquake at a shallow depth below the slope surface, groundwater seeped rapidly into the slope through the fissures. Since the underlying mudstone formation was a relatively impermeable layer, the groundwater tended to flow along the interface of the dolomite and shale.

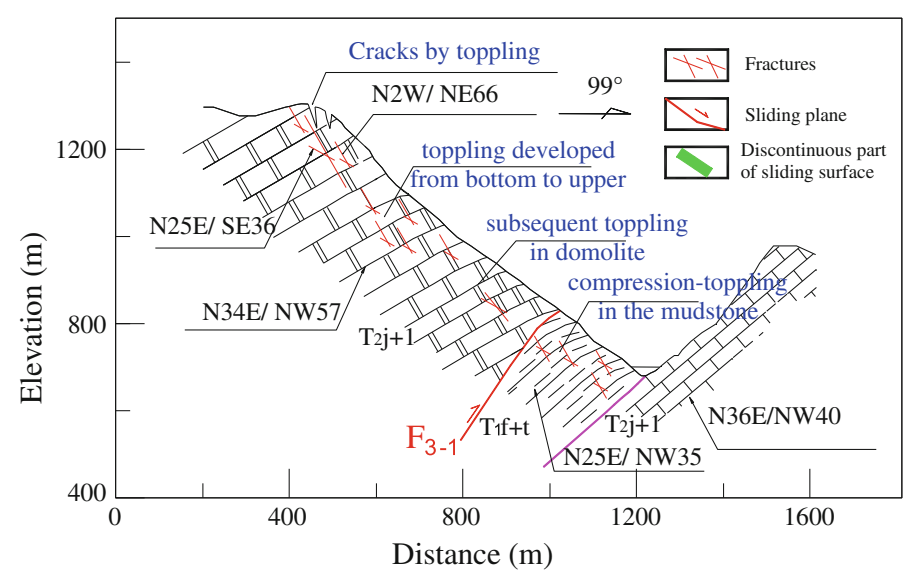

Fig. 9 Development of toppling deformation as the result of compression in underlying mudstones 


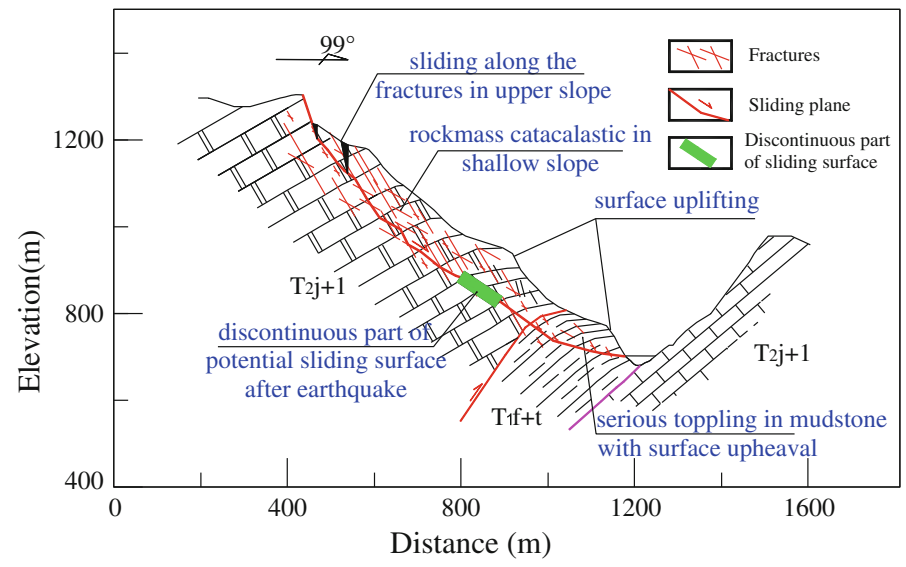

Fig. 10 Intense deformation occurred at the lower and upper parts of the slope with upheavals on the surface of middle and lower parts. The upper part of the slope slid down as the result of the Wenchuan earthquake. The subsequent heavy rain accelerated the slope deformation and cut through the sliding plane

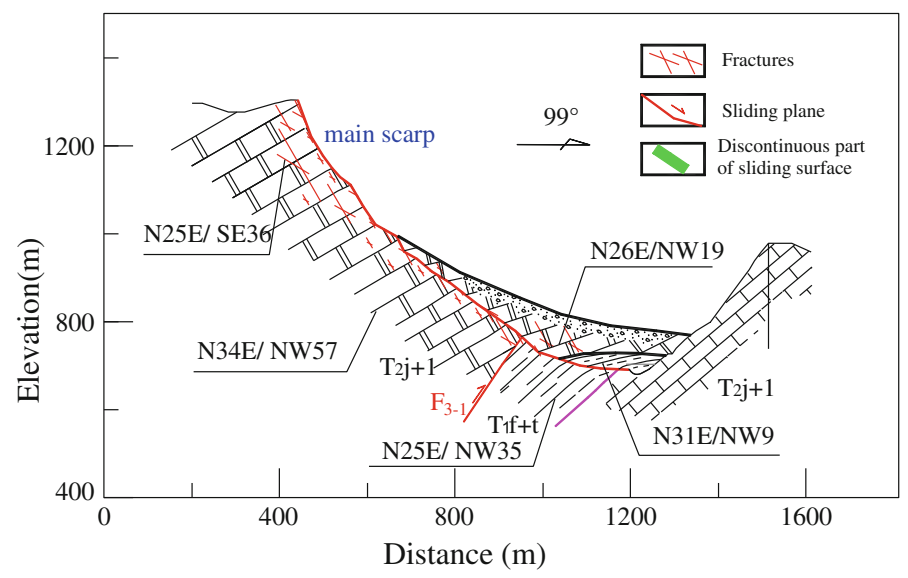

Fig. 11 The whole slope slid along the continuous gliding plane and deposited on the Jushui river

High hydrostatic and hydrodynamic pressures were generated by the groundwater filling in the fractures. The condition has promoted further formations of new fissures in rock. In addition, the groundwater has also led to saturation and softening of mudstone. As creeping and discontinuous sliding surface has been developed in the slope after the earthquake, the groundwater that seeped through the interface caused a further reduction in shear strength of rock mass and hence triggered the failure (Fig. 11). The collapse of the main slope structure produced a huge "booming sound," and the subsequent rock falls persisted leading to rumbles.

\subsection{Prediction of horizontal depth of sliding mass}

The seismic waves of the Wenchuan earthquake, particularly the horizontal waves, resulted in formations of new fractures in the hard rocks as indicated by the toppling deformation 
observed at the upper part of the slope. The horizontal depth of the actual sliding mass can be estimated through correlations between the slope height and the location of the maximum horizontal acceleration amplification in the slope.

For the hard rock slope model, the maximum horizontal acceleration amplification occurred at a depth of $0.2 \mathrm{~m}$ from the slope surface. The height of the slope model was $1.7 \mathrm{~m}$. By employing this ratio, it was anticipated that the maximum horizontal acceleration amplification would occur at a depth of $40.23 \mathrm{~m}$ from the slope surface for the actual 342-m-high Guantan slope. This estimated depth was very close to the actual depth of the sliding plane $(38 \mathrm{~m})$ observed at site.

For the soft rock slope model that has the same height as the hard rock model, the maximum horizontal acceleration amplification was captured at a depth of $0.45 \mathrm{~m}$ from the slope surface. By adopting the similar ratio as above, the maximum horizontal acceleration amplification was predicted to occur at a depth of $43.4 \mathrm{~m}$ from the slope surface, given the height of the soft rock in the actual Guantan landslide was $164 \mathrm{~m}$. This estimated depth also provided a reasonably good comparison with the actual depth of the sliding plane developed in the soft rock $(42 \mathrm{~m})$. These results showed that the maximum horizontal acceleration can be used as a good indicator for the location of sliding plane.

From the observations above, two simple equations were developed empirically for predicting the depth of sliding plane in the hard rock and soft rock slopes, respectively:

$$
L_{h}=0.2 H_{h} / 1.7
$$

$L_{h}$ - the depth of sliding plane from slope surface in hard rock slopes

$H_{h}$ - the height of hard rock slopes

$$
L_{s}=0.45 H_{s} / 1.7
$$

$L_{s}$ - the depth of sliding plane from slope surface in soft rock slopes

$H_{s}$ - the height of the soft rock slopes

Equations 1 and 2 correlate the location of sliding plane with the height of slope. However, it should be noted that slope height is just one of many factors (i.e., slope gradient, lithology, slope structure, discontinuities, ground water, earthquake parameters, etc.) that may influence the development of sliding plane in a slope. More rigorous shaking table tests and field monitoring results are required to establish a more comprehensive relationship between the sliding plane and the maximum acceleration. Besides, the shaking table tests in this study were performed using a single-layered rock mass. The dynamic responses of layered strata, such as the one observed at the actual Guantan landslide site warrant an interesting future study. The influence of underlying soft rock stratum on the overlying hard rock stratum requires further clarification.

\section{Conclusion}

The Guantan landslide is a typical example of earthquake-induced landslide on an anti-dip slope with a weak founding stratum. The case study offers a useful insight into the relationship between geological factors and occurrence of earthquake-induced landslide. In this study, the seismic influence on the slope and the failure mechanism of the Guantan landslide were studied by field investigations and large scale shaking table tests.

The shaking table tests successfully described the deformation phenomena of the earthquake-induced landslides. The deformation of the hard rock slope mainly developed within a shallow depth in the upper part of the slope, while the deformation of the soft rock 
slope concentrated at the upper (near the crest) and lower (near the toe) parts of the slope. The location of sliding plane in the model was consistent with the location of the maximum horizontal acceleration. Based on the horizontal depth of the sliding plane developed in the Guantan landslide, two equations were proposed for predicting the horizontal depth of sliding planes for hard and soft rock slopes. Finally, the failure processes of the landslide were summarized into three stages: (1) toppling deformation caused by compression of the underlying soft rock stratum, (2) formation of cataclastic hard rock and sliding surface in soft rock as the result of seismic shock, particularly in the horizontal direction, and (3) aftershock rainfall accelerates the process of mass movement along the sliding surface. The seismic shock, particularly in the horizontal direction, strongly governed the location of the sliding surface.

Acknowledgments This study is financially supported by the State Key Laboratory of Geohazard Prevention and Geoenvironment Protection (Chengdu University of Technology) (Grant No. SKLGP2009Z013), the National Basic Research Program of China (973 Program) (Grant No. 2013CB733202) and the Key Project of National Natural Science Foundation of China (Grant No. 41130745).

Open Access This article is distributed under the terms of the Creative Commons Attribution License which permits any use, distribution, and reproduction in any medium, provided the original author(s) and the source are credited.

\section{References}

Ayonghe SN, Mafany G, Ntasin E, Samalang P (1999) Seismically activated swarm of landslides, tension cracks and rock fall in Bafaka, Cameroon. Nat Hazards 19:13-27

Chang KJ, Taboada A, Lin ML, Chen RF (2005) Analysis of landsliding by earthquake shaking using a block-on-slope thermo-mechanical model: example of Jiufengershan landslide, central Taiwan. Eng Geol 80:151-163

Chigira M, Yagi H (2006) Geological and geomorphological characteristics of landslides triggered by the 2004 Mid Niigta prefecture earthquake in Japan. Eng Geol 82:202-221

Hsieh Y-M, Lee K-C, Jeng F-S, Huang T-H (2011) Can tilt tests provide correct insight regarding frictional behavior of sliding rock block under seismic excitation? Eng Geol 122:84-92

Huang RQ (1996) Studies of the geological model and formation mechanism of Xikou landslide. In: Balkema AA (ed) Proceedings of the 7th international symposium on landslides, pp 1671-1678

Huang RQ (2012) Mechanisms of large-scale landslides in China. Bull Eng Geol Environ 71:161-170

Huang R, Li W (2009a) Development and distribution of geohazards triggered by the 5.12 Wenchuan Earthquake in China. Sci China Ser E-Technol Sci 52:810-819

Huang RQ, Li WL (2009b) Analysis of the geo-hazards triggered by the 12 May 2008 Wenchuan Earthquake, China. Bull Eng Geol Environ 68:363-371

Huang CC, Horng JC, Chang WJ, Chiou JS, Chen CH (2011a) Dynamic behavior of reinforced wallsHorizontal displacement response. Geotext Geomembr 29:257-267

Huang RQ, Xu QA, Huo JJ (2011b) Mechanism and geo-mechanics models of landslides triggered by 5.12 Wenchuan Earthquake. J Mt Sci 8:200-210

Huang Y, Zhang W, Xu Q, Xie P, Hao L (2012) Run-out analysis of flow-like landslides triggered by the Ms 8.0 2008 Wenchuan earthquake using smoothed particle hydrodynamics. Landslides 9:275-283

Katz O, Reichenbach P, Guzzetti F (2011) Rock fall hazard along the railway corridor to Jerusalem, Israel, in the Soreq and Refaim valleys. Nat Hazards 56(3):649-665

Keefer D (1984) Landslides caused by earthquakes. Geol Soc Am Bull 95:406-421

Kieffer DS, Jibson R, Rathje EM, Kelson K (2006) Landslides triggered by the 2004 Niigata Ken Chuetsu, Japan, earthquake. Earthq Spectra 22:S47-S73

Lin ML, Wang KL (2006) Seismic slope behavior in a large-scale shaking table model test. Eng Geol $86: 118-133$

Lin CW, Liu SH, Lee SY, Liu CC (2006) Impacts of the Chi-Chi earthquake on subsequent rainfall-induced landslides in central Taiwan. Eng Geol 86:87-101 
Newmark NM (1965) Effects of earthquakes on dams and embankments. Geotechnique 15(2):139-160

Qi S, Xu Q, Lan H, Zhang B, Liu J (2010) Spatial distribution analysis of landslides triggered by 2008.5.12 Wenchuan Earthquake, China. Eng Geol 116:95-108

Rodriguez CE, Bommer JJ, Chandler RJ (1999) Earthquake induced landslides: 1980-1997. Soil Dyn Earthq Eng 18:325-346

Severn RT (2011) The development of shaking tables: a historical note. Earthq Eng Struct Dyn 40(2):195-213

Wakai A, Ugai K, Onoue A, Kuroda S, Higuchi K (2009) Finite element simulation for earthquake-induced landslide based on strain-softening characteristics of weathered rocks. In:Proceeding of international symposium on prediction and simulation methods for geohazard mitigation (IS-Kyoto 2009), Kyoto, Japan, May 25-27 2009, pp 167-172

Wang KL, Lin ML (2011) Initiation and displacement of landslide induced by earthquake: a study of shaking table model slope test. Eng Geol 122(1-2):106-114

Wang JA, Yao LK, Hussain A (2010) Analysis of earthquake-triggered failure mechanisms of slopes and sliding surfaces. J Mt Sci 7:282-290

Wang Y, Huang R, Luo Y, Xu H (2011) The genetic mechanism of Wenchuan earthquake. J Mt Sci 8:336-344

Wartman J, Seed RB, Bray JD (2005) Shaking table modeling of seismically induced deformations in slopes. J Geotech Geoenviron Eng 131:610-622

Wasowski J, Keefer DK, Lee C-T (2011) Toward the next generation of research on earthquake-induced landslides: current issues and future challenges. Eng Geol 122:1-8

Wei YC, Lee CJ, Hung WY, Chen HT (2010) Application of Hilbert-Huang transform to characterize soil liquefaction and quay wall seismic responses modeled in centrifuge shaking-table tests. Soil Dyn Earthq Eng 30(7):614-629

Wen X-Z, Zhang P-Z, Du F, Long F (2009) The background of historical and modern seismic activities of the occurrence of the $2008 \mathrm{M}(\mathrm{S}) 8.0$ Wenchuan, Sichuan, earthquake. Chin J Geophys Chin Edn 52:444-454

Wilson RC, Keefer DK (1983) Dynamic analysis of a slope failure from the 6 August, 1979 Coyote Lake, California, earthquake. Seismol Soc Am Bull 73(3):863-877

Xu Q, Fan X-M, Huang R-Q, Van Westen C (2009) Landslide dams triggered by the Wenchuan Earthquake, Sichuan Province, south west China. Bull Eng Geol Environ 68:373-386

Xu Q, Liu HX, Zou W (2010) Large-scale shaking table test study of acceleration dynamic responses characteristics of slopes. Chin J Rock Mech Eng 12:2420-2428

Xu Q, Zhang S, Li W (2011) Spatial distribution of large-scale landslides induced by the 5.12 Wenchuan Earthquake. J Mt Sci 8:246-260

Yin Y, Wang F, Sun P (2009) Landslide hazards triggered by the 2008 Wenchuan earthquake, Sichuan, China. Landslides 6:139-152

Zhang ZY, Wang ST, Wang LS (1994) Theory of engineering geological analysis. Chinese Geoligic Press, Beijing

Zhang RR, Ma S, Safak E, Hartzel S (2003) Hilbert-Huang transform analysis of dynamic and earthquake motion recordings. ASCE J Eng Mech 129(8):861-875

Zhang Y, Chen G, Wu J, Zheng L, Zhuang X (2012) Numerical simulation of seismic slope stability analysis based on tension-shear failure mechanism. Geotech Eng 43:18-28

Zhao JJ, Ju NP, Li G, and Huang RQ (2010) Failure mechanism analysis of Guantan landslide induced by Wenchuan Earthquake. J Geol Hazards Environ Preserv 21:92-96 (in Chinese) 